\title{
Reflectance Confocal Microscopy as New Diagnostic Tool in Folliculotropic Mycosis Fungoides
}

\author{
Gabriella Fabbrocini $^{\mathrm{a}} \quad$ Caterina Mazzella $^{\mathrm{a}}$ Mariateresa Cantelli ${ }^{\mathrm{a}}$ \\ Antonello Baldo ${ }^{a}$ Daniela Russo ${ }^{b}$ Gaetano De Rosa ${ }^{b}$ Giuseppe Monfrecola ${ }^{a}$ \\ ${ }^{a}$ Dermatology Unit, Department of Clinical Medicine and Surgery, and b Pathology Section, Department of \\ Advanced Biomedical Sciences, University Federico II, Naples, Italy
}

\section{Established Facts}

- Folliculotropic mycosis fungoides (FMF) is an aggressive variant of cutaneous T-cell lymphoma.

- FMF can imitate a wide variety of otherwise benign dermatoses and thus pose major diagnostic obstacles both for the dermatologist as well as the dermatopathologist.

\section{Novel Insights}

- Reflectance confocal microscopy (RCM) has a potential role for the evaluation of inflammatory skin diseases.

- RCM can reduce the number of unsuccessful histopathological examinations and increase the diagnostic accuracy for different skin dermatoses.

\section{Keywords}

Confocal microscopy · Cutaneous T-cell lymphoma ·

Follicular mycosis fungoides · Hair microscopy

\section{Abstract}

We present a case of folliculotropic mycosis fungoides (FMF), a variant of cutaneous T-cell lymphoma which particularly affects hair follicles. FMF can imitate a wide variety of otherwise benign dermatoses, so it poses major diagnostic obstacles both for the dermatologist as well as the dermatopathologist. In our case, in vivo reflectance confocal micros- (c) 2017 S. Karger AG, Basel

E-Mail karger@karger.com www.karger.com/sad copy (RCM) was very important for guiding the skin biopsy site selection. For this reason, RCM can reduce the number of unsuccessful histopathological examinations and increase the diagnostic accuracy for different skin dermatoses.

(c) 2017 S. Karger AG, Basel

\section{Introduction}

Folliculotropic mycosis fungoides (FMF) has been designated by the new World Health Organization-European Organization for Research and Treatment of Cancer 
classification system for cutaneous lymphomas as a distinct variant of cutaneous T-cell lymphoma [1]. In vivo reflectance confocal microscopy (RCM) is a noninvasive tool for examination of inflammatory skin disease, including T-cell lymphomas [2,3] and scalp diseases [4]. We report a current utilization of RCM as a guide for skin biopsy.

\section{Case Report}

A 51-year-old male presented with patchy alopecia on his legs with multiple itchy follicular whitish-pink papules for 4 years (Fig. 1). Objective skin examination was normal and familiar anamnesis was negative for dermatologic diseases. The first diagnostic consideration was follicular mucinosis. Skin biopsy on the thigh revealed a slightly thinned epidermis and a dermis characterized by fibrosis, adnexal atrophy, and a large plug of keratin. The pathologist excluded the diagnosis of follicular mucinosis, suggesting an unusual variant of lichen planopilaris.

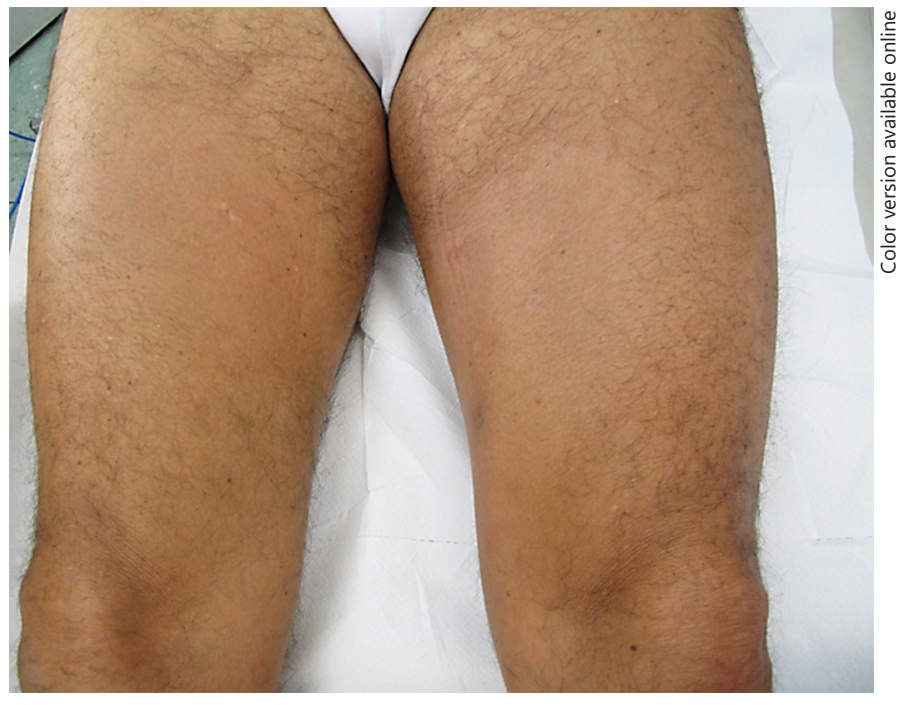

Fig. 1. Clinical presentation: patchy alopecia on the legs with multiple follicular whitish-pink papules.
Fig. 2. Confocal microscopy presentation: an infiltrate of small weakly refractile round to oval cells in the epidermis (a) with disorganized honeycomb pattern (b); refractile filamentous thick structures around the follicular structure (c); refractile round to oval cells of the remaining infundibular follicular structure (d).
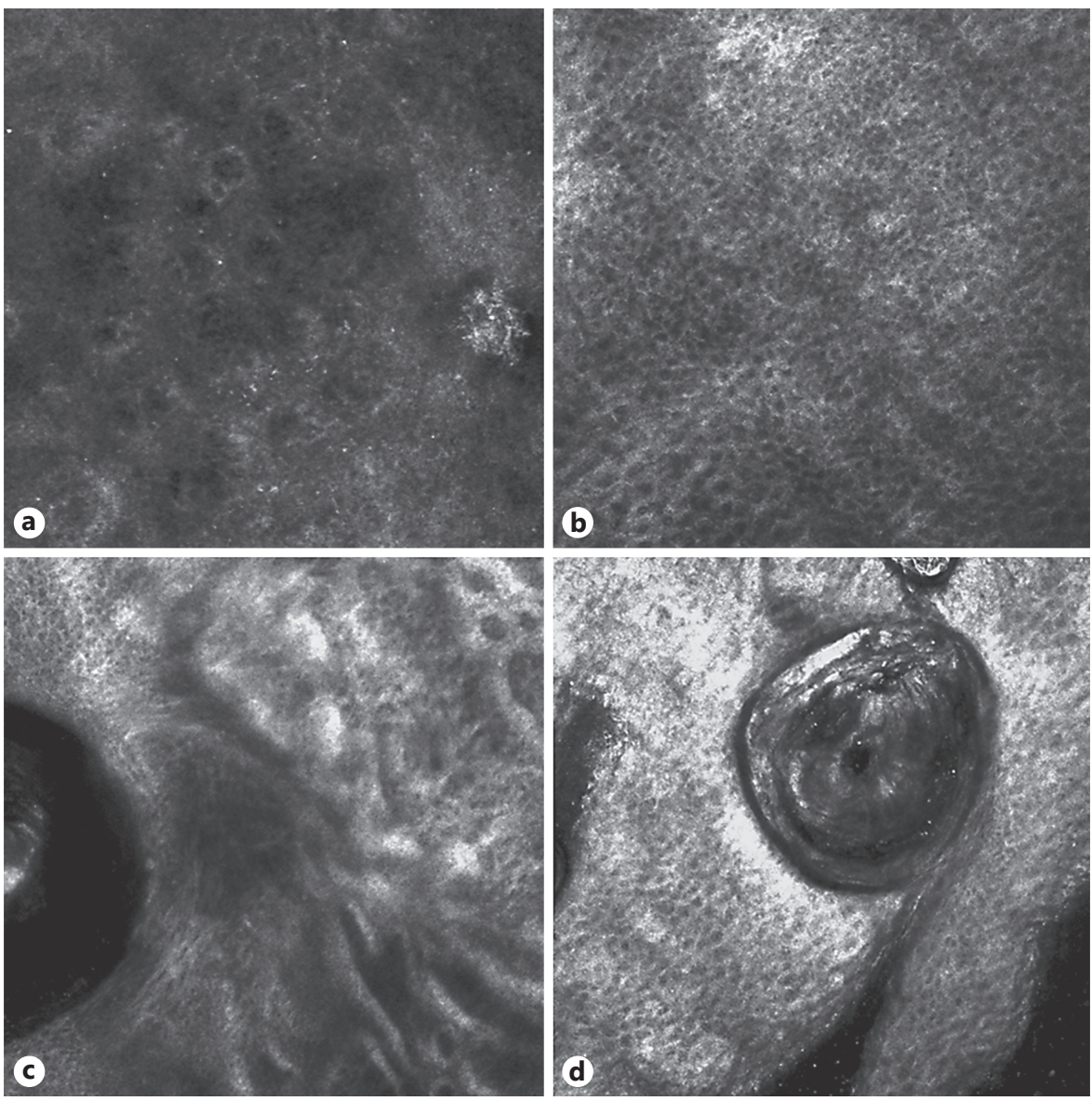


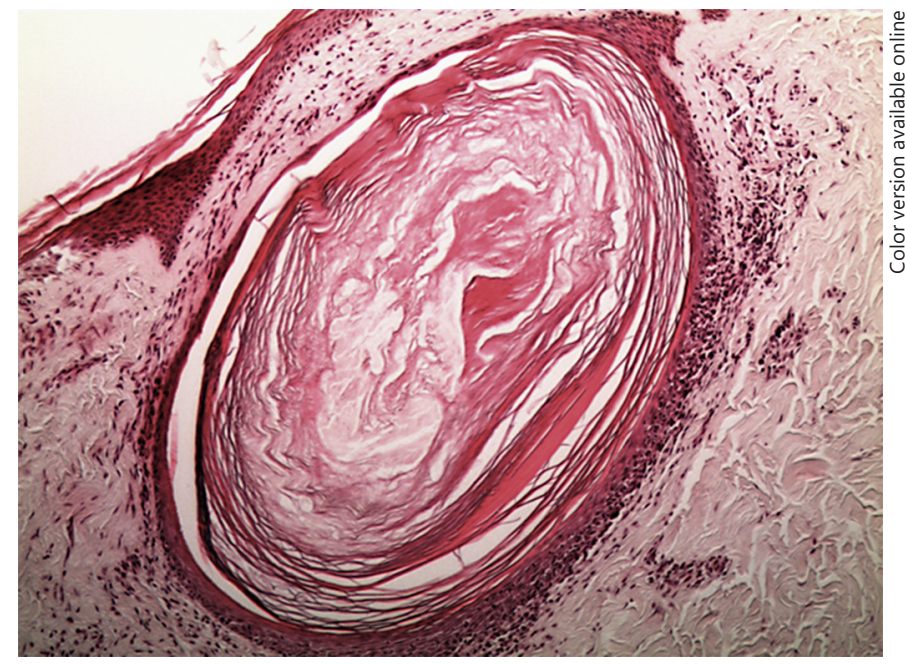

Fig. 3. Histology presentation: a dense, band-like focally epidermotropic and folliculotropic lymphoid infiltrate.

So we performed RCM, which showed in a few sites of the affected areas an infiltrate of small, weakly refractile round to oval cells in the epidermis (Fig. 2a) with a disorganized honeycomb pattern (Fig. 2b) along with diffuse sclerosis of the upper dermis with thickening of dermal fibers and inflammatory cells (Fig. 2c). Furthermore, RCM showed a close-up view of the hair follicle containing keratin and refractile round to oval cells around and within the pilosebaceous unit (Fig. 2d). A skin biopsy was repeated on the site selected by RCM and revealed a dense, band-like focally epidermotropic and folliculotropic lymphoid infiltrate (Fig. 3). The number of hair follicles was reduced. A polymerase chain reaction study of the T-cell receptor gamma chain gene revealed a monoclonal band. A diagnosis of FMF was made. The patient was classified, according to the TNM classification, as stage IA mycosis fungoides.

\section{Discussion}

FMF is an aggressive variant of cutaneous T-cell lymphoma and it seems to be more prevalent in males [5]. The time interval between first symptoms and the diagnosis is reported to be about 4 years. Pruritus is very common in FMF [5]. FMF is sometimes associated with follicular mucinosis. Most cases of FMF show mucinous degeneration of the hair follicles and are traditionally designated as mycosis fungoides-associated follicular mucinosis [6].

FMF can imitate a wide variety of otherwise benign dermatoses and thus pose major diagnostic obstacles both for the dermatologist as well as the dermatopathol- ogist [7]. In such cases, associated dermatopathological findings may also closely imitate its benign counterpart, i.e., psoriasiform epidermal hyperplasia in psoriasis vulgaris-like variants of mycosis fungoides, subepidermal blisters in bullous pemphigoid-like presentations, interstitial histiocytes and giant cells in granuloma annularelike mycosis fungoides, or interface dermatitis in mycosis fungoides with lichen planus-like skin lesions [8,9]. In our case, the histopathology of the first biopsy corresponds to an unusual lichen planopilaris. Histopathology of lichen planopilaris demonstrates a lymphocytic infiltrate concentrated between the follicular infundibulum and isthmus with vacuolar degeneration of the basal layer and destruction of basal keratinocytes and destruction of hair follicle root sheaths and follicular plugging [10].

In the last few years, RCM has demonstrated a potential role for the evaluation of inflammatory skin diseases. In our case, RCM (Vivascope ${ }^{\circledR} 3000$, Caliber I.D., Rochester, NY, USA) was useful to compare the histopathological findings and it optimizes the site selection of skin biopsy. RCM could potentially reduce the number of nondiagnostic biopsies and increase the diagnostic accuracy for different skin dermatoses. The limitation of RCM in FMF is the inability to characterize the epidermal infiltrate as lymphocytic and the loss of resolution of the dermis. It is also operator dependent and it requires time for the analysis: the evaluation of images is subordinated to the interpretation of the specialist and therefore dependent on his experience. The cost of the confocal microscopy could be cushioned by using it on large numbers of patients, so its use should be made in reference centers.

\section{Statement of Ethics}

The patient signed informed consent to publish details of his data. All procedures conformed to the guidelines set forth by the Declaration of Helsinki.

\section{Disclosure Statement}

The authors have no conflicts of interest to disclose. 


\section{References}

1 Willemze R, Jaffe ES, Burg G, Cerroni L, Berti E, Swerdlow SH, Ralfkiaer E, Chimenti S, Diaz-Perez JL, Duncan LM, Grange F, Harris NL, Kempf W, Kerl H, Kurrer M, Knobler R, Pimpinelli N, Sander C, Santucci M, Sterry W, Vermeer MH, Wechsler J, Whittaker S, Meijer CJ: WHO-EORTC classification for cutaneous lymphomas. Blood 2005; 105:37683785.

2 Ardigò M, El Shabrawi-Caelen L, Tosti A: In vivo reflectance confocal microscopy assessment of the therapeutic follow-up of cutaneous T-cell lymphomas causing scalp alopecia. Dermatol Ther 2014;27:248-251.
3 Agozzino M, Tosti A, Barbieri L, Moscarella E, Cota C, Berardesca E, Ardigò M: Confocal microscopic features of scarring alopecia: preliminary report. Br J Dermatol 2011:165: 534-540.

4 Lehman JS, Cook-Norris RH, Weed BR, Weenig RH, Gibson LE, Weaver AL, Pittelkow MR: Folliculotropic mycosis fungoides: single-center study and systematic review. Arch Dermatol 2010;146:607-613.

5 Muniesa C, Estrach T, Pujol RM, Gallardo F, Garcia-Muret P, Climent J, Servitje O: Folliculotropicmycosis fungoides: clinicopathological features and outcome in a series of 20 cases. J Am Acad Dermatol 2010;62:418-426.

6 Hooper KK, Smoller BR, Brown JA: Idiopathic follicular mucinosis or mycosis fungoides? Classification and diagnostic challenges. $\mathrm{Cu}-$ tis 2015;95:E9-E14.
7 Spieth K, Grundmann-Kollmann M, Runne U, Staib G, Fellbaum C, Wolter M, Kaufmann R, Gille J: Mycosis-fungoides-type cutaneous $\mathrm{T}$ cell lymphoma of the hands and soles: a variant causing delay in diagnosis and adequate treatment of patients with palmoplantar eczema. Dermatology 2002;205:239-244.

8 Kneitz H, Bröcker EB, Becker JC: Mycosis fungoides bullosa: a case report and review of the literature. J Med Case Rep 2010;4:78.

9 Fink-Puches R, Wolf P, Kerl H, Cerroni L: Lichen aureus: clinicopathologic features, natural history, and relationship to mycosis fungoides. Arch Dermatol 2008;144:1169-1173.

10 Assouly P, Reygagne P: Lichen planopilaris: update on diagnosis and treatment. Semin Cutan Med Surg 2009;28:3-10. 